\title{
Mycobactins and Exochelins of Mycobacterium tuberculosis, M. bovis, M. africanum and Other Related Species
}

\author{
By RAYMOND BARCLAY† AND COLIN RATLEDGE* \\ Department of Biochemistry, University of Hull, Hull HU6 $7 R X, U K$
}

(Received 20 August 1987; revised 13 November 1987)

\begin{abstract}
Following iron-deficient growth, mycobactins and exochelins were isolated from 11 strains of Mycobacterium tuberculosis (including type strains of the virulent $\mathrm{H} 37 \mathrm{Rv}$ and avirulent $\mathrm{H} 37 \mathrm{Ra}$ organisms) as well as from $M$. bovis (one strain), $M$. bovis BCG (two strains), $M$. africanum (eight strains) and $M$. xenopi (one strain) but not from $M$. microti (one strain). The mycobactins from the tuberculosis group (M.tuberculosis, M. bovis and $M$. africanum) were identical and could each be resolved into four compounds by thin-layer chromatography (TLC) and into several fractions by high-performance liquid chromatography, supporting previous claims that this group is a single taxon. Exochelins were all chloroform-soluble and showed no species specificity; no single exochelin was recognized by TLC that had not been previously seen in $M$. avium or a related species.
\end{abstract}

\section{INTRODUCTION}

Like virtually all living organisms, pathogenic mycobacteria need iron. To meet the demand for iron, mycobacteria synthesize and utilize specific high-affinity iron-binding compounds which help them grow in the iron-restricted conditions of the host (Kochan et al., 1971, Barclay \& Ratledge, 1983, 1986 a, b) and also participate in the uptake of iron across the thick lipid cell wall (Ratledge, 1982). Two types of iron-binding compound are produced (Ratledge, 1982): mycobactin, which is cell-associated, and exochelin, which is secreted into the extracellular environment. Mycobactins themselves differ structurally, and the types of mycobactin which are produced are determined by the species (Snow, 1970; Hall, 1986). Mycobacterium tuberculosis has been known for some time to produce one (Snow, 1965) or two mycobactins (White \& Snow, 1968), but no comparison has been made between the mycobactins produced by virulent and avirulent tubercle bacilli, or between tubercle and closely related mycobacteria such as $M$. bovis, $M$. africanum and $M$. microti, which are usually grouped together as members of the 'tuberculosis' complex (Goodfellow \& Wayne, 1982).

Nothing has been published about the exochelins of $M$. tuberculosis though it has been known for some time that the related $M$. bovis BCG produces a chloroform-soluble exochelin (Macham et al., 1975). Chloroform-soluble exochelins seem to be important in the pathogenesis of other virulent mycobacteria such as $M$. avium and $M$. paratuberculosis (Barclay \& Ratledge, 1983; Barclay et al., 1985; Barclay \& Ratledge, 1986a,b; Momotani et al., 1986). In this report we have examined some of the properties of the mycobactins and exochelins from virulent and avirulent strains of $M$. tuberculosis and related organisms, and compared them to those of other pathogenic mycobacteria.

$\dagger$ Present address: Department of Microbiology, University of Reading, London Road, Reading RGI 5AQ, UK.

Abbreviation: MAIS, Mycobacterium avium, $M$. intracellulare and $M$. scrofulaceum group of organisms. 


\section{METHODS}

Organisms and growth. The type of strains of $M$. tuberculosis used were NCTC 7417 (H37Ra) and NCTC 7416 (H37Rv). Freshly isolated strains of $M$. tuberculosis from P. A. Jenkins (PHLS Mycobacterium Reference Unit, University Hospital of Wales, Cardiff, UK) were strains 13398, 13661, 13965, 13968, 13969, 14039, 14043, 14045 and 14048. Isolates of M. africanum were from M. D. Yates (PHLS Regional Centre for Tuberculosis Bacteriology, Public Health Laboratory, Dulwich Hospital, London, UK) and included strains 40083, 40433, 40452, 40544, $41120,41168,41190$ and 41396 . Strains of $M$. bovis were NCTC 10772, and NCTC 5692 (BCG); $M$. avium strain M3 and $M$. intracellulare strain M12 were as described before (Barclay \& Ratledge, 1983); M. microti (NCTC 8710), M. triviale (ATCC 23292) and $M$. xenopi (NCTC 10042) were also used. Strains were grown on an iron-deficient ( $\left.20 \mathrm{ng} \mathrm{Fe} \mathrm{ml}^{-1}\right)$ glycerol/asparagine/mineral salts medium $(100 \mathrm{ml})$ which was prepared in iron-free glassware (Ratledge \& Hall, 1971). Incubation was at $37^{\circ} \mathrm{C}$ for 8 weeks without shaking. Iron-sufficient growth was on the same medium with $2 \mu \mathrm{g} \mathrm{Fe} \mathrm{ml}^{-1}$.

Mycobactin and exochelin isolation. Mycobactins were isolated by ethanol extraction of freshly harvested, moist mycobacterial cells (Snow, 1970). Exochelins were converted to their ferri-complexes and extracted into chloroform from cell-free culture filtrates (Macham et al., 1975).

Thin-layer chromatography (TLC) of mycobactins and exochelins. The method used was that of Barclay \& Ratledge (1983), with $250 \mu \mathrm{m}$ thick silica gel 60 plates with concentrating zones (Merck). Mycobactins and exochelins were chromatographed with light petroleum (b.p. $\left.60-80^{\circ} \mathrm{C}\right) / \mathrm{n}$-butanol/ethyl acetate $(2: 3: 3$, by vol.). Exochelins were also separated with ethanol/light petroleum/ethyl acetate $(1: 4: 6$, by vol.).

High-performance liquid chromatography (HPLC). The method was adapted from that of Barclay et al. (1985) using a $20 \times 0.25 \mathrm{~cm}$ column packed with Lichrosorb RP-18 with a solvent flow rate of $2 \mathrm{ml} \mathrm{min}^{-1}$. For mycobactin and for exochelin separation, the mobile phase was initially $60 \%(\mathrm{v} / \mathrm{v})$ methanol in water increasing to methanol only at a constant rate over $10 \mathrm{~min}$. The mobile phase was thereafter maintained as $100 \%$ methanol.

Autoradiography. Exochelins in culture filtrates were labelled with ${ }^{55} \mathrm{Fe}$, extracted into chloroform and separated by TLC, all as described by Barclay \& Ratledge (1983). The solvents were completely removed from the TLC plates by air-drying. Autoradiography of the plates was then done with Kodak X-Omat RB X-ray film $(18 \times 24 \mathrm{~cm})$ with an exposure for $7 \mathrm{~d}$ at room temperature.

\section{RESULTS AND DISCUSSION}

\section{Production of mycobactin and exochelin}

Twenty-three strains of $M$. tuberculosis and related species of mycobacteria were examined for the production of mycobactin and exochelin, after iron-deficient growth. All eleven strains of $M$. tuberculosis, three of $M$. bovis, including two of BCG, and eight of $M$. africanum produced both mycobactin and exochelin but $M$. microti (one strain only) appeared to produce neither. Production of mycobactin and exochelin reached a maximum after 6-8 weeks with the amounts produced varying according to the strain used (Table 1). The ability of the tuberculosis group to produce exochelin decreased with repeated subculture in laboratory growth media, whilst mycobactin production increased. This phenomenon has also been observed for members of the MAIS group, i.e. M. avium, $M$. intracellulare, $M$. scrofulaceum and $M$. paratuberculosis (Barclay \& Ratledge, 1983).

\section{Mycobactins}

Mycobacteria may be differentiated by the mobility of their mycobactins in TLC systems and this is a useful tool in the classification of most mycobacteria (Ratledge, 1987). Early reports suggested that $M$. tuberculosis probably produced two mycobactins (White \& Snow, 1968), but improved TLC techniques now show that there are four main components (Table 2). Furthermore, the separation pattern with respect to the $R_{F}$ values of the four components was consistent for the mycobactins from the tubercle and related bacilli (M. bovis, $M$. bovis BCG and $M$. africanum) but differed from that of other mycobacterial species (Table 2). The virulent (e.g. H37Rv) and avirulent (H37Ra) strains of tubercle bacilli had identical separation patterns for their mycobactins. Other TLC solvent systems, which had been used successfully to differentiate the mycobactins of other species (Barclay \& Ratledge, 1983; Barclay et al., 1985), failed to differentiate the mycobacteria of the tuberculosis group (results not shown).

Mycobactins can also be differentiated by the nature of their long alkyl chains using HPLC. This separation differs from that of the TLC method, which relies on variations in the polar 
Table 1. Production of mycobactins and chloroform-soluble exochelins by organisms of the tuberculosis group after 8 weeks at $37^{\circ} \mathrm{C}$

Results are means of four experiments.

\begin{tabular}{|c|c|c|c|c|}
\hline \multirow[b]{2}{*}{$\begin{array}{l}\text { Mycobacterium species } \\
\text { and strain no.* }\end{array}$} & \multicolumn{2}{|c|}{$\begin{array}{c}\text { Mycobactin production } \\
{\left[\mu \mathrm{g}(\mathrm{g} \text { cell dry } \mathrm{wt})^{-1}\right]}\end{array}$} & \multicolumn{2}{|c|}{$\begin{array}{l}\text { Exochelin production } \\
{\left[\mu \mathrm{g}(\mathrm{g} \text { cell dry } \mathrm{wt})^{-1}\right]}\end{array}$} \\
\hline & $\begin{array}{l}\text { Iron- } \\
\text { sufficient } \\
\text { growth }\end{array}$ & $\begin{array}{c}\text { Iron- } \\
\text { deficient } \\
\text { growth }\end{array}$ & $\begin{array}{c}\text { Iron- } \\
\text { sufficient } \\
\text { growth }\end{array}$ & $\begin{array}{l}\text { Iron- } \\
\text { deficient } \\
\text { growth }\end{array}$ \\
\hline \multicolumn{5}{|l|}{ M. tuberculosis } \\
\hline NCTC H37Ra & 1492 & 3852 & 531 & 1074 \\
\hline NCTC H37Rv & ND & 1455 & ND & 1032 \\
\hline 13398 & ND & 1324 & ND & 938 \\
\hline 13661 & ND & 2036 & ND & 1282 \\
\hline 13965 & 794 & 1836 & 64 & 1118 \\
\hline 13968 & ND & 4302 & ND & 1142 \\
\hline 13969 & 274 & 4222 & 488 & 604 \\
\hline 14039 & 454 & 920 & 1032 & 3402 \\
\hline 14043 & 226 & 700 & 1478 & 2700 \\
\hline 14045 & 554 & 670 & 20 & 1026 \\
\hline 14048 & 0 & 1200 & 398 & 562 \\
\hline \multicolumn{5}{|l|}{ M. africanum } \\
\hline 40083 & ND & 55 & ND & 636 \\
\hline 40433 & ND & 1135 & ND & 384 \\
\hline 40452 & ND & 956 & ND & 126 \\
\hline 40544 & ND & 1554 & ND & 1128 \\
\hline 41168 & ND & 0 & ND & 796 \\
\hline 41190 & ND & 0 & ND & 662 \\
\hline 41396 & ND & 1327 & ND & 0 \\
\hline M. bovis $\mathrm{BCG}$ & 298 & 453 & 108 & 411 \\
\hline M. microti & 0 & 0 & 0 & 0 \\
\hline M. xenopi & ND & 4166 & ND & 102 \\
\hline M. triviale & ND & 132 & ND & 403 \\
\hline
\end{tabular}

ND, Not determined.

* For origin of strains see Methods.

Table 2. Identification of mycobactins by $T L C$

Source of mycobactin

Avirulent $M$. tuberculosis (H37Ra)

Relative percentage $(w / w) \dagger$

Virulent $M$. tuberculosis (H37Rv)

$M$. bovis

$M$. bovis $\mathrm{BCG}$

M. africanum

M. xenopi

M. avium
No. of strains examined

$\begin{array}{cc}1 & 0.45 \\ 10 & (15 \%) \\ 1 & 0.45 \\ 2 & 0.45 \\ 8 & 0.45 \\ 1 & 0.45 \\ \ddagger & \end{array}$

$R_{F}$ in given solvent system*

$\begin{array}{ccc}0.48 & 0.60 & 0.64 \\ (22 \%) & (35 \%) & (28 \%) \\ 0.48 & 0.60 & 0.64 \\ 0.48 & 0.60 & 0.64 \\ 0.48 & 0.60 & 0.64 \\ 0.48 & 0.60 & 0.64 \\ 0.81 & & \\ 0.89 & & \end{array}$

* Light petroleum/butanol/ethyl acetate $(2: 3: 3$, by vol.).

+ Calculated by elution with ethanol and determination of absorbance at $450 \mathrm{~nm}$.

$\ddagger$ From Barclay et al. (1985).

nucleus of the molecule (Barclay et al., 1985), and consequently the elution profiles given by the two processes bear no relationship to each other. HPLC has been used successfully to resolve mycobactins of slow-growing and rapidly growing mycobacteria (Barclay et al., 1985; Hall \& Ratledge, 1984, 1985a,b), but had not been applied to those from tubercle bacilli. The elution profile for $M$. tuberculosis H37Ra (Fig. 1) was typical in its major features of all the tubercle and 


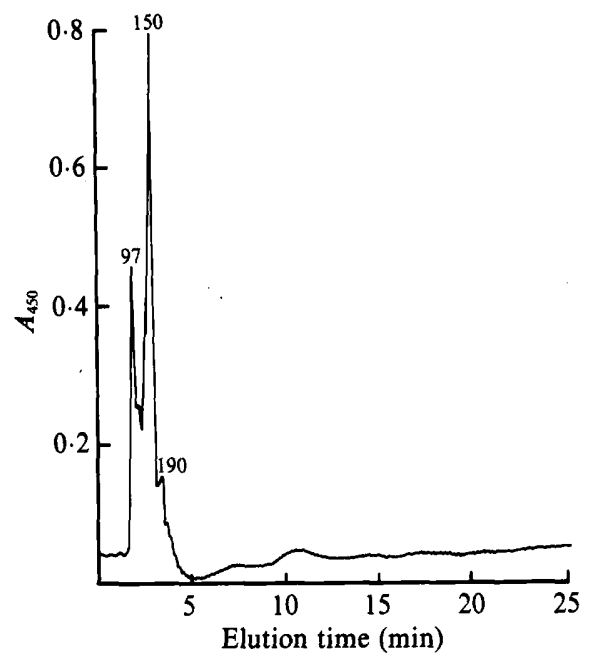

Fig. 1

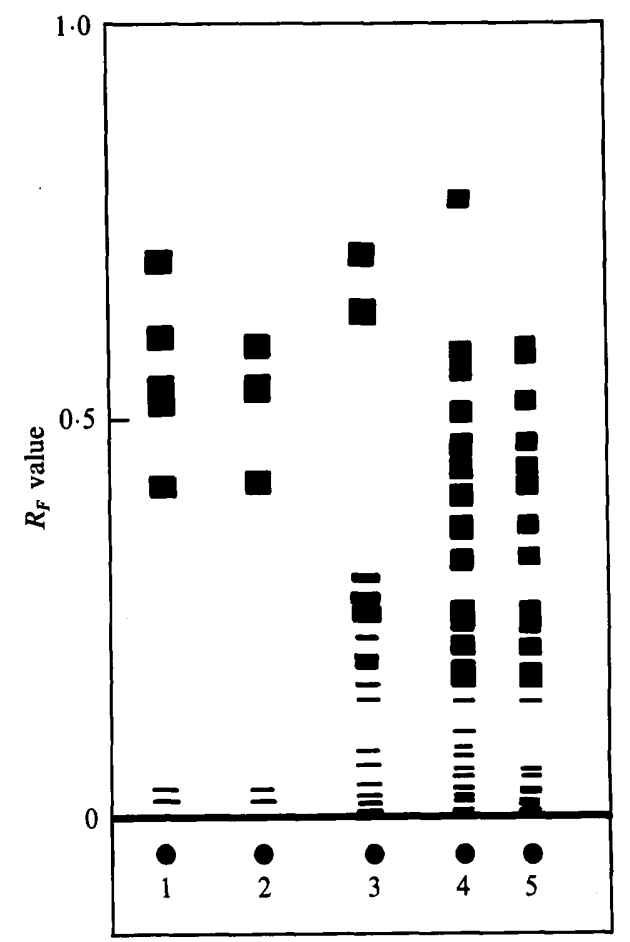

Fig. 2

Fig. 1. Reverse-phase HPLC of mycobactins from $M$. tuberculosis $\mathrm{H} 37 \mathrm{Ra}$ on a Lichrosorb RP 18 column with a gradient of $60 \%(\mathrm{v} / \mathrm{v})$ methanol in water rising to $100 \%$ methanol in $10 \mathrm{~min}$. Elution times (in seconds) of the major peaks are indicated.

Fig. 2. Autoradiograph after TLC (light petroleum/butanol/ethyl acetate; $2: 3: 3$ by vol.) of exochelins (extracellular ${ }^{55} \mathrm{Fe}$-binding compounds) from M. tuberculosis strain 13965 (lane 1), 13969 (lane 2), 13968 (lane 3), H37Ra (lane 4) and H37Rv (lane 5).

related bacilli described in Table 1, and was distinct from that of other unrelated mycobacteria (Barclay et al., 1985; Hall \& Ratledge, 1984, 1985a,b). Unlike the mycobactins of the MAIS group (Barclay et al., 1985; Barclay \& Ratledge, 1983, 1986a,b), the mycobactins of the tuberculosis group could not be used to differentiate the individual members of the group by HPLC.

\section{Exochelins}

Exochelins in the culture filtrates of the organisms described in Table 1 were labelled with ${ }^{55} \mathrm{Fe}$ and extracted with chloroform as before (Barclay \& Ratledge, 1983), separated by TLC and then autoradiographed. Each sample separated into a number of bands of radioactivity (Fig. 2) that corresponded to the orange (exochelin) bands visible on the TLC plate. The patterns were similar in complexity to those previously recorded for the exochelins of the MAIS and $M$. paratuberculosis groups (Barclay \& Ratledge, 1983). No exochelin components from the tubercle bacilli were found that had not been previously seen with the MAIS and $M$. paratuberculosis groups. Furthermore, no radiolabelled components were found remaining in the culture filtrates after chloroform extraction, which would suggest that no water-soluble exochelin was produced. Thus, a common and distinct property of most of the slow-growing pathogenic mycobacteria is the ability to produce a number of related chloroform-soluble exochelins.

The ferri-exochelins from the mycobacterial strains shown in Table 1, as well as those of $M$. avium M3, $M$. intracellulare M12 and $M$. paratuberculosis strain 18, were further examined by 


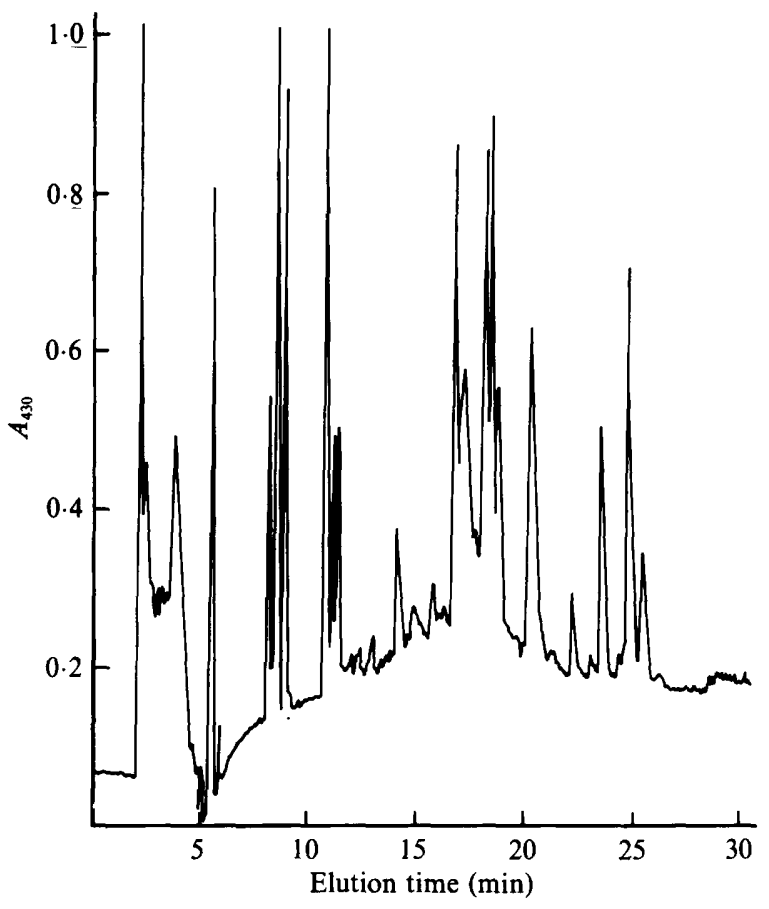

Fig. 3. Reverse-phase HPLC of exochelins from $M$. tuberculosis H37Ra on a Lichrosorb RP 18 column with a gradient of $60 \%(\mathrm{v} / \mathrm{v})$ methanol in water rising to $100 \%$ methanol in $10 \mathrm{~min}$.

HPLC, a single example of which is shown in Fig. 3. Other solvent systems incorporating methanol, acetonitrile, propan-1-ol and water under various gradient systems were examined but were not as effective as the methanol/water gradient system (results not shown). All exochelins exhibited differing elution patterns, similar in complexity to that shown in Fig. 3, but no differences occurred which could be construed as the result of species differentiation. Thus, the exochelins are unlikely to be of use as chemotaxonomic characters in differentiating mycobacteria but the data obtained by both TLC and HPLC analyses confirms the closerelatedness of this group of iron-chelating materials from the tubercle, MAIS and $M$. paratuberculosis groups of mycobacteria.

One of the aims of studying iron-uptake mechanisms of pathogenic mycobacteria is to pinpoint new sites for antimycobacterial drugs. The finding that the 'tuberculosis' group of organisms produce extracellular iron-binding compounds that are unique to them and other slow-growing mycobacterial pathogens such as the MAIS group, including $M$. paratuberculosis, is therefore of great interest. This is particularly so given that exochelins are produced mostly by freshly isolated strains than by laboratory-subcultured ones and suggests that exochelins are the preferred means of acquiring iron in the host. These findings make it likely that an understanding of the iron-uptake mechanisms of any one of the slow-growing pathogens will result in an understanding of them all. Furthermore, the similarity in the exochelins produced by the mycobacteria of the 'tuberculosis' group to those produced by the MAIS group is of taxonomic interest, and suggests that these pathogens may have evolved by a pathway distinct from that of the saprophytes.

We have shown that like the other major species the tuberculosis group, with the exception of $M$. microti, produce characteristic mycobactins. Unlike the mycobactins from the MAIS group, those from the tuberculosis group could not be differentiated by HPLC which further reinforces the view that these organisms belong to a single taxon (Goodfellow \& Wayne, 1982). However, as the attenuated strains, such as $M$. tuberculosis $\mathrm{H} 37 \mathrm{Ra}$ and $M$. bovis $\mathrm{BCG}$, produce the same mycobactins and exochelins as their more virulent counterparts, it is clear that although an 
effective iron-uptake system is essential to a pathogen, siderophore production in itself is not a sole virulence determinant of tubercle bacilli. Nonetheless, inhibition of iron uptake into these bacilli would be potentially useful for the inhibition of their growth in vivo.

This work was supported by a research grant from the Medical Research Council.

\section{REFERENCES}

Barclay, R. \& Ratledge, C. (1983). Iron binding compounds of Mycobacterium avium, $M$. intracellulare, $M$. scrofulaceum, and mycobactin-dependent $M$. paratuberculosis and M. avium. Journal of Bacteriology 153, 1138-1146.

BarClay, R. \& RATledge, C. (1986a). Participation of iron on the growth inhibition of pathogenic strains of Mycobacterium avium and $M$. paratuberculosis in serum. Zentralbatt für Bakteriologie, Mikrobiologie und Hygine (Series A) 262, 189-194.

Barclay, R. \& Ratledge, C. (1986 b). Metal analogues of mycobactin and exochelin fail to act as effective antimycobacterial agents. Zentralblatt für Bakteriologie, Mikrobiologie und Hygiene (Series A) 262, 203-207.

Barclay, R., Ewing, D. F. \& Ratledge, C. (1985). Isolation, identification and structural analysis of the mycobactins of Mycobacterium avium, $\mathrm{Myco}$ bacterium intracellulare, Mycobacterium scrofulaceum and Mycobacterium paratuberculosis. Journal of Bacteriology 164, 896-903.

GoOdfellow, M. \& WAYNE, L. G. (1982). Taxonomy and nomenclature. In The Biology of the $\mathrm{Myco-}$ bacteria, vol. 1, pp. 471-521. Edited by C. Ratledge \& J. L. Stanford. London: Academic Press.

HaLl, R. M. (1986). Mycobactins: how to obtain them and how to employ them as chemotaxonomic characters for the mycobacteria and related organisms. Actinomycetes 19, 92-106.

Hall, R. M. \& RATLEDGE, C. (1984). Mycobactins as chemotaxonomic characters for some rapidly growing mycobacteria. Journal of General Microbiology 130, 1883-1892.

Hall, R. M. \& Ratledge, C. (1985a). Equivalence of mycobactins from Mycobacterium senegalense, Mycobacterium farcinogenes and Mycobacterium fortuitum. Journal of General Microbiology 131, 16911696.

Hall, R. M. \& Ratledge, C. (1985b). Mycobactins in the classification and identification of armadilloderived mycobacteria. FEMS Microbiology Letters 28, 243-247.

Kochan, J., Pelis, N. R. \& Golden, C. A. (1971). Mechanisms of tuberculosis in mammalian serum. III. Neutralization of serum tuberculosis by mycobactin. Infection and Immunity 3, 553-558.

Macham, L. P., Ratledge, C. \& Nocton, J. C. (1975). Extracellular iron acquisition by mycobacteria: role of exochelins and evidence against the participation of mycobactin. Infection and Immunity 12, 1242 1251.

Momotani, E., Furugouri, K., Obara, Y., Miyata, Y., IsHIKAWA, Y. \& Yoshino, T. (1986). Immunohistochemical distribution of ferritin, lactoferrin and transferrin in granulomas of bovine paratuberculosis. Infection and Immunity 52, 623-627.

RATLEDGE, C. (1982). Nutrition, growth and metabolism. In The Biology of the Mycobacteria, vol. 1, pp. 185-221. Edited by C. Ratledge \& J. L. Stanford. London: Academic Press.

RATLEDGE, C. (1987). Iron metabolism in Mycobacterium. In Iron transport in Microbes, Plants and Animals, pp. 207-233. Edited by G. Winkelmann, D. van der Helm \& J. B. Neilands. Weinheim: VCH.

RATLEDGE, C. \& HALL, M. J. (1971). Influence of metal ions on the formation of mycobactin and salicylic acid in Mycobacterium smegmatis grown in static culture. Journal of Bacteriology 108, 314-319.

SNOw, G. A. (1965). Isolation and structure of mycobactin T, a growth factor from Mycobacterium tuberculosis. Biochemical Journal 97, 166-175.

SNow, G. A. (1970). Mycobactins: iron-chelating growth factors from mycobacteria. Bacteriological Reviews 34, 99-125.

White, A. J. \& SNow, G. A. (1968). Methods for the separation and identification of mycobactins from various species of mycobacteria. Biochemical Journal 108, 593-597. 